\title{
Prevalence and correlates of posttraumatic stress disorder and chronic severe pain in psychiatric outpatients
}

\author{
Cherie L. Villano, PsyD; ${ }^{1}$ Andrew Rosenblum, PhD; ${ }^{1 *}$ Stephen Magura, PhD; ${ }^{1}$ Chunki Fong; ${ }^{1}$ Charles Cle- \\ land, PhD; ${ }^{1}$ Thomas F. Betzler, MD $^{2}$ \\ ${ }^{1}$ National Development and Research Institutes, Inc, New York, NY; ${ }^{2}$ Albert Einstein College of Medicine, Bronx, NY
}

\begin{abstract}
This cross-sectional study reports the prevalence and correlates of posttraumatic stress disorder (PTSD) and chronic severe pain in psychiatric outpatients $(n=295)$, a sample that has not previously been examined for the co-occurrence of these two disorders. Nearly half the participants (46\%) met the Diagnostic and Statistical Manual of Mental Disorders-Fourth Edition criteria for PTSD; 40\% reported chronic severe pain; and $24 \%$ had both disorders. We compared four groups of subjects who had either both disorders, PTSD only, chronic severe pain only, or neither disorder for variables previously found to be associated with both disorders or either disorder alone (e.g., psychiatric distress, substance use, stressful life events, physi$\mathrm{cal} /$ sexual abuse). Multiple pairwise comparisons indicated that persons with both disorders were significantly different from persons with neither disorder for all dependent variables and that they had greater physical and psychosocial stressors. Persons with either PTSD or chronic severe pain alone were more likely to have a chronic medical condition, higher ratings of psychiatric distress, and more stressful life events than persons with neither disorder. Mental health treatment providers should be aware of the potential for the co-occurrence of PTSD and chronic severe pain and of the many related factors in psychiatric outpatients.
\end{abstract}

Key words: chronic medical condition, chronic pain, mental health, physical/sexual abuse, positive affect, posttraumatic stress disorder, psychiatric outpatients, social support, stressful life events, substance use.

\section{INTRODUCTION}

Recent research has demonstrated that posttraumatic stress disorder (PTSD) and chronic pain frequently co-occur [1-2]. Persons with PTSD commonly report chronic pain, and persons with chronic pain report more severe PTSD symptoms [3-4]. When these two disorders cooccur, they appear to amplify and complicate the patient's experience. Chronic pain patients also diagnosed with PTSD report higher pain intensity, more emotional distress, and greater pain-related interference and disability than those without PTSD [5]. Data from the National Comorbidity Survey [6] indicated that persons reporting chronic musculoskeletal pain were four times

\footnotetext{
Abbreviations: ANOVA $=$ analysis of variance, ASI $=$ Addiction Severity Index, BPI = Brief Pain Inventory, CAPS = ClinicianAdministered Posttraumatic Stress Disorder Scale, DSM-IV = Diagnostic and Statistical Manual of Mental Disorders-Fourth Edition, HSD = honest significant difference, M.I.N.I. = MiniInternational Neuropsychiatric Interview, PA = positive affect, PTSD = posttraumatic stress disorder, SMI $=$ severe mental illness, SUD = substance-use disorder.

*Address all correspondence to Andrew Rosenblum, PhD; National Development and Research Institutes Inc, Institute for Treatment and Services Research, 71 West 23rd St, 8th Floor, New York, NY 10010; 212-845-4528; fax: 917-4380894. Email: rosenblum@ndri.org

DOI: 10.1682/JRRD.2006.05.0052
} 
more likely to develop PTSD than persons without such pain [7]. PTSD treatment studies demonstrating improvements in pain symptoms also point toward the overlap of PTSD and chronic pain [8]. ${ }^{*}$ Several researchers have postulated that PTSD and chronic pain are intricately connected [9-10] and that similar psychological, physiological, and behavioral mechanisms are responsible for the two disorders (e.g., fear and avoidance, somatic focus, anxiety sensitivity, “catastrophizing”) $[1,3,11]$.

Prevalence rates for PTSD in the general population have been reported at 6 percent for males and 12 percent for females [6]. The prevalence of chronic pain in the general population is conservatively estimated at 10 to 20 percent [12-13]. Chronic pain is typically defined as pain that persists for at least 3 to 6 months [14]. Recent research on PTSD and chronic pain has been conducted mainly on veterans, chronic pain patients, and PTSD patients. For veterans with PTSD, Shipherd et al. found that 66 percent had a comorbid diagnosis of chronic pain. ${ }^{*}$ Asmundson et al. reported that 44 percent of female veterans with PTSD (full or subsyndromal) scored higher on pain experience and pain interference ratings (i.e., how much pain interfered with daily functioning) [2]. For a group of firefighters with PTSD, McFarlane et al. found that approximately 45 percent reported significant back pain [15]. Several studies on veterans and nonveterans with chronic pain and fibromyalgia reported that 10-35 percent also met diagnostic criteria for PTSD [16-18]. In studies of persons with pain from a motor vehicle accident, researchers found that rates of PTSD ranged from 30-50 percent [19-21]. Thus, the research on veterans, chronic pain patients, and PTSD patients demonstrates that PTSD and chronic pain frequently co-occur.

The co-occurrence of PTSD and chronic pain has not been examined in the general psychiatric outpatient population (i.e., nonveteran patients). The prevalence of PTSD alone and the likelihood of continued trauma and violence have been documented in psychiatric patients [22-23]. Craine et al. reported that 34 percent of women admitted to inpatient psychiatric treatment were diagnosed with PTSD [24]. Cascardi et al. found that 29 percent of persons recently admitted to inpatient psychiatric

\footnotetext{
*Shipherd JC, Keyes M, Jovanovic T, Ready DJ, Baltzell D, Worley V, Gordon-Brown V, Duncan E. Intensive PTSD treatment in a veteran sample with comorbid chronic pain: Evidence of generalized effects. Unpublished observations; 2005.
}

treatment also had PTSD [25]. Mueser et al. reported that 43 percent of psychiatric outpatients with severe mental illness (SMI) also had PTSD [23]. Gearon et al. found that 46 percent of schizophrenic women (psychiatric outpatients) had PTSD [26]. Mueser et al. found that 35 percent of persons with SMI (psychiatric outpatients and inpatients) had PTSD [27]. Despite these research findings, PTSD is not typically recognized or formally diagnosed in mental health (or primary care) treatment settings. Mueser and colleagues reported that PTSD rates of 29-43 percent were found in prior studies on psychiatric patients with SMI, but less than 5 percent of those patients had PTSD documented in their medical records [28]. The underdiagnosis of PTSD is both a clinical and financial problem because PTSD contributes to ongoing substance use, potential victimization, continued psychiatric or medical problems, and increased health-services use [27].

While psychiatric comorbidity in chronic pain patients has been studied extensively, we found no study documenting chronic pain or the co-occurrence of chronic pain and PTSD in psychiatric outpatients. We sought to examine the rates of PTSD, chronic pain, and the co-occurrence of these two disorders in a sample of psychiatric outpatients. We speculated that PTSD would be underdiagnosed in the current sample, similar to prior research on the incidence of PTSD in psychiatric patients [28]. Our aim was also to compare four groups of subjects who had either both disorders, PTSD only, chronic severe pain only, or neither disorder for variables previously found to be associated with comorbid PTSD and chronic pain or with either disorder alone. In accordance with prior research, we hypothesized that persons in our sample with comorbid PTSD and chronic severe pain would be more likely to have a chronic medical condition (i.e., a cause of chronic pain) and emotional/psychiatric distress. We also hypothesized that persons with both or a single disorder would be more likely to demonstrate psychosocial stressors (e.g., more stressful life events, lower ratings of social support and positive affect [PA]), than persons with neither disorder. Finally, we hypothesized that the pattern of these associations would be most robust when persons with both disorders were compared with those with neither disorder. 


\section{METHODS}

\section{Participants}

From March 2003 to June 2005, men and women newly admitted to an urban outpatient mental health clinic were recruited to participate in a research interview for an experimental study of self-help groups. Patients were referred and admitted to the study clinic from various mental health and drug treatment settings, including inpatient psychiatric units, mental health residences, other outpatient mental health clinics, outpatient drug treatment clinics (including methadone maintenance treatment programs), or they were self-referred through community contacts. The study protocol was approved by the respective institutional review boards of the host research site (Albert Einstein College of Medicine, Bronx, New York) and the organization that conducted the study (National Development and Research Institutes Inc, New York, New York). Participants were excluded from study participation if they were younger than 18, did not understand or speak English, appeared intoxicated on drugs or alcohol, were diagnosed with mental retardation, were deemed actively psychotic by the clinic's intake coordinator, or appeared unable to understand and give informed consent. Of 668 potential participants screened for recruitment, 61 percent $(n=408)$ signed the informed consent and agreed to participate, 25 percent $(n=169)$ refused to participate, and 17 percent $(n=91)$ were excluded for the above-mentioned reasons. Of those who signed consent forms, 72 percent $(n=$ 295) completed the initial interview within 1 month of program admission. Participants who signed consent forms but failed to complete the interview within 4 weeks were dropped from the study because the baseline interview focused on the time period prior to clinic admission. Participants who failed to complete the interview within 4 weeks were typically not attending the program consistently, refused to complete the interview after signing consent, may have been transferred to another outpatient or inpatient facility, or may have dropped out of treatment entirely. Confidential research interviews were conducted by trained research assistants using laptop computers with Questionnaire Design Studio software (NOVA Research Company, Bethesda, Maryland). Participants were compensated $\$ 20$ for the 90-minute research interview.

\section{Measures}

The interview consisted of a battery of questions that assessed demographics, drug use, drug treatment, psychiatric history, physical health, and various psychosocial domains. A diagnosis of PTSD was acquired with the PTSD module from the Mini-International Neuropsychiatric Interview (M.I.N.I.) [29], a widely used, valid, and reliable measure of psychiatric conditions based on criteria from the Diagnostic and Statistical Manual of Mental Disorders-Fourth Edition (DSM-IV). Pain measures were adapted from the Brief Pain Inventory (BPI) [30]. Participants were asked to indicate the severity of their pain at its worst in the past week. The extent to which pain interfered with different domains (e.g., sleep, mood, walking) in the past week was assessed with the 7-item BPI pain interference subscale; this subscale has been widely validated, and the association between pain severity and interference has been established empirically [31]. The pain severity and interference subscales each had a 10point numeric rating scale. Chronic severe pain was defined as (1) a score $\geq 5$ on the BPI pain severity scale or $\geq 5$ on the interference scale and (2) pain duration of more than 6 months. Thus, we defined a measure of chronic severe pain using pain severity or interference ratings in combination with pain duration; this was the same measure we used in a previous study of chemical dependency patients [32]. We created a combined variable indicating the presence of either both disorders or neither disorder using the PTSD and chronic severe pain variables.

We measured psychiatric distress by computing a mean score from a 10-item version of the widely used 90-item Symptom Checklist [33]. PA was measured with the 10-item PA scale from the Positive and Negative Affect Schedule [34]. Stressful or traumatic life events were measured with a summed score from the Stressful Life Events Inventory [35], a 19-item inventory that asks participants whether they have ever experienced a variety of stressful events (e.g., been a victim of a violent crime, experienced domestic violence, been evicted or lost their home). We evaluated recent drug use by combining a self-report variable (e.g., days using drugs and alcohol in the 30 days prior to admission) with biological measures of drug use (urinalysis and hair immunoassay). We used the M.I.N.I. subscale for a substance-use disorder (SUD) to diagnose participants with a current SUD (past year) [29]. The M.I.N.I. subscales for SUD and PTSD were chosen for faster administration and adequate reliability and validity, rather than the more commonly used Structured 
Clinical Interview for DSM-III-R (revised Third edition) or the Composite International Diagnostic Interview. An addiction severity measure was generated by combining the drug- and alcohol-scale scores from the Addiction Severity Index (ASI) (Fifth edition) [36]. The ASI has been widely used for more than 25 years, and the reliability of the drug and alcohol scales for psychiatric patients has been noted [37]. Participants' confidence to cope with aspects of their mental illness was measured with a mean score from the Mental Health Confidence Scale [38], a valid and reliable scale that measures psychiatric patients' mental health related self-efficacy beliefs (i.e., optimism, coping, and advocacy). We measured lifetime physical/sexual abuse by combining three questions regarding unwanted sexual contact or physical abuse from family members or others (e.g., "Did anybody in your family, or someone you were close to or living with, ever make you engage in sexual acts against your will?”). We evaluated chronic medical problems by asking participants, "Do you currently have a chronic physical or medical problem that interferes with your life?” Because we could find no brief instrument that measured participants' perceptions of social support for recovery specifically from mental illness and substance use, we created a 6-item Likert scale to measure this parameter (e.g., "In the month before you came to this program, how much support were your friends/relatives/ roommates giving you in recovering from mental illness/ substance abuse?”); Cronbach alpha (internal consistency) for this scale was adequate at 0.76 . In addition, we reviewed participants' medical records approximately 6 months after clinic admission to obtain data on DSM-IV Axis I psychiatric diagnoses (including PTSD) provided by psychiatrists in the continuing day treatment program.

\section{Statistical Procedures}

We calculated univariate statistics to examine demographic variables, including the percentage of participants who met diagnostic criteria for PTSD, SUD, and DSM-IV Axis I psychiatric diagnoses (obtained from medical records). We also calculated percentages for chronic severe pain, any recent drug use prior to admission, any stressful life events, any lifetime physical/ sexual abuse, and chronic medical problems. We created a combined variable to compare four groups of subjects who had either both PTSD and chronic severe pain, PTSD only, chronic severe pain only, or neither disorder. Bivariate correlations explored associations among 16 variables of interest and either any PTSD, any chronic severe pain, both disorders, or neither disorder. To minimize inferential errors, we adjusted the $p$-value using the Bonferroni method of correction [39]; thus, the significance level for the bivariate correlations was set at $p<0.003$ $(0.05 / 16$ variables $=0.003)$. To compare differences among the four mutually exclusive groups (PTSD only, chronic severe pain only, both disorders, or neither disorder), we used variables that were significant at the bivariate level as dependent variables in chi-square analysis and one-way analysis of variance (ANOVA); each group was compared with each of the other groups. We used Tukey's honest significant difference (HSD) [40] as the post hoc test to determine significant differences between groups in the ANOVAs.

\section{RESULTS}

Demographic information and descriptive statistics for the entire sample $(n=295)$ are shown in Table 1. Of particular interest, 46 percent of participants $(n=135)$ met M.I.N.I. diagnostic criteria for PTSD, 40 percent of participants $(n=118)$ met criteria for chronic severe pain, and 24 percent of participants $(n=71)$ met criteria for both disorders. When we examined subjects with a single disorder, 22 percent $(n=64)$ had PTSD (but no chronic severe pain) and 16 percent $(n=47)$ had chronic severe pain (but no PTSD). DSM-IV Axis I psychiatric diagnostic information obtained from medical records is presented in Table 2. Of note, only 7 percent of participants were assigned a primary or secondary PTSD diagnosis by a clinic psychiatrist.

Table 3 shows the bivariate correlations of either both disorders, any PTSD, any chronic severe pain, or neither disorder with demographic characteristics and 16 other variables. The comparisons among the four mutually exclusive groups are presented in Table 4 for chisquare analyses and Table 5 for ANOVAs. For the chisquare analyses, the percentage of participants with any abuse or a chronic medical condition across the four groups is presented alongside the between-groups comparisons. For the one-way ANOVAs, the mean score for each continuous dependent variable across the four groups is presented alongside the between-groups significance tests (Tukey's HSD). Persons with both disorders were significantly different from persons with neither disorder on all dependent variables. Patients with both 
JRRD, Volume 44, Number 2, 2007

Table 3.

Bivariate correlations (Pearson's $r)^{*}(n=295)$.

\begin{tabular}{|c|c|c|c|c|}
\hline Independent Variable & $\begin{array}{l}\text { Both PTSD and CSP } \\
\qquad(n=71)\end{array}$ & $\begin{array}{l}\text { Any PTSD } \\
(n=135)\end{array}$ & $\begin{array}{l}\text { Any CSP } \\
(n=118)\end{array}$ & $\begin{array}{c}\text { Neither PTSD } \\
\text { nor CSP } \\
(n=113)\end{array}$ \\
\hline$\overline{\text { Age }}$ & 0.14 & 0.08 & $0.26^{*}$ & $-0.22^{*}$ \\
\hline Sex & 0.11 & 0.15 & 0.08 & -0.14 \\
\hline Caucasian & 0.15 & 0.07 & 0.16 & -0.10 \\
\hline African American & -0.15 & -0.12 & -0.13 & 0.12 \\
\hline Hispanic & 0.05 & 0.06 & 0.00 & -0.02 \\
\hline Currently in MMTP & 0.10 & 0.06 & 0.16 & -0.14 \\
\hline Chronic Medical Condition & $0.25^{*}$ & $0.19^{*}$ & $0.32^{*}$ & $-0.30^{*}$ \\
\hline Psychiatric Distress & $0.36^{*}$ & $0.34^{*}$ & $0.37^{*}$ & $-0.41^{*}$ \\
\hline Physical/Sexual Abuse & $0.18^{*}$ & 0.15 & $0.18^{*}$ & $-0.18^{*}$ \\
\hline Positive Affect & -0.17 & -0.04 & $-0.18^{*}$ & 0.08 \\
\hline Stressful Life Event & $0.28^{*}$ & $0.28^{*}$ & $0.26^{*}$ & $-0.31^{*}$ \\
\hline Social Support & -0.17 & -0.12 & $-0.19^{*}$ & 0.17 \\
\hline Substance-Use Disorder & 0.16 & 0.15 & 0.11 & -0.12 \\
\hline Drug Use (past 30 d) & 0.11 & 0.12 & 0.12 & -0.16 \\
\hline Addiction Severity Rating & $0.24^{*}$ & $0.21^{*}$ & $0.21^{*}$ & $-0.21^{*}$ \\
\hline Mental Health Confidence & $-0.29^{*}$ & $-0.25^{*}$ & $-0.25^{*}$ & $0.25^{*}$ \\
\hline
\end{tabular}

Table 4.

Between-group chi-square analyses.

\begin{tabular}{|c|c|c|c|c|}
\hline \multirow[b]{2}{*}{ Dependent Variable ${ }^{*}$} & \multirow[b]{2}{*}{$\%$} & \multicolumn{3}{|c|}{ Chi-Square Analysis ${ }^{\dagger}$} \\
\hline & & $\begin{array}{l}\text { Neither PTSD nor CSP } \\
\qquad(n=113)\end{array}$ & $\begin{array}{l}\text { PTSD Only } \\
\quad(n=64)\end{array}$ & $\begin{array}{c}\text { CSP Only } \\
(n=47)\end{array}$ \\
\hline \multicolumn{5}{|l|}{ Any Physical/Sexual Abuse } \\
\hline Neither PTSD nor CSP & 38.2 & - & - & - \\
\hline PTSD Only & 50.0 & No & - & - \\
\hline CSP Only & 53.2 & No & No & - \\
\hline Both PTSD and CSP & 66.2 & Yes & No & No \\
\hline \multicolumn{5}{|l|}{ Chronic Medical Condition } \\
\hline Neither PTSD nor CSP & 20.4 & - & - & - \\
\hline PTSD Only & 35.9 & Yes & - & - \\
\hline CSP Only & 53.2 & Yes & No & - \\
\hline Both PTSD and CSP & 60.2 & Yes & Yes & No \\
\hline
\end{tabular}

have higher ratings of psychiatric distress and addiction severity, report more stressful life events, and have lower ratings of $\mathrm{PA}$, social support, and confidence to cope with mental illness compared with persons with neither disorder. In prior studies, PTSD and chronic pain separately have shown associations with many of the factors found in the current study: physical/sexual abuse [26,41], chronic physical health problems [32,42], psychiatric or emotional distress [43-44], drug/alcohol use [45-46], ongoing stressful or traumatic life events [26,47], and lower social support [48-49]. In previous studies, chronic pain was associated with increased age [32] and lower PA [50]; therefore, that persons with both disorders in the current study demonstrated these characteristics is logical. A novel finding was that persons with both disorders had lower confidence for coping with mental illness (e.g., 
coping with negative affect, staying out of the psychiatric

demonstrating that the increased cognitive demands asso-

hospital). This result is in accordance with recent research

Table 5.

Between-group one-way analysis of variance (ANOVA) with post hoc comparison (Tukey’s honest significant difference).

\begin{tabular}{|c|c|c|c|c|}
\hline \multirow{2}{*}{ Dependent Variable ${ }^{*}$} & \multirow{2}{*}{ Mean \pm SD } & \multicolumn{3}{|c|}{ One-Way ANOVA $^{\dagger}$} \\
\hline & & Neither PTSD nor CSP & PTSD Only & CSP Only \\
\hline \multicolumn{5}{|l|}{ Age } \\
\hline Neither PTSD nor CSP & $36.21 \pm 10.20$ & - & - & - \\
\hline PTSD Only & $38.06 \pm 9.73$ & No & - & - \\
\hline CSP Only & $42.91 \pm 8.63$ & Yes & Yes & - \\
\hline Both PTSD and CSP & $41.23 \pm 7.45$ & Yes & No & No \\
\hline \multicolumn{5}{|l|}{ Psychiatric Distress } \\
\hline Neither PTSD nor CSP & $1.26 \pm 0.95$ & - & - & - \\
\hline PTSD Only & $1.88 \pm 0.90$ & Yes & - & - \\
\hline CSP Only & $1.98 \pm 1.04$ & Yes & No & - \\
\hline Both PTSD and CSP & $2.48 \pm 0.92$ & Yes & Yes & Yes \\
\hline \multicolumn{5}{|l|}{ Positive Affect } \\
\hline Neither PTSD nor CSP & $3.15 \pm 1.02$ & - & - & - \\
\hline PTSD Only & $3.28 \pm 1.00$ & No & - & - \\
\hline CSP Only & $2.92 \pm 1.21$ & No & No & - \\
\hline Both PTSD and CSP & $2.72 \pm 1.11$ & Yes & Yes & No \\
\hline \multicolumn{5}{|l|}{ Stressful Life Events } \\
\hline Neither PTSD nor CSP & $5.75 \pm 4.01$ & - & - & - \\
\hline PTSD Only & $7.91 \pm 4.05$ & Yes & - & - \\
\hline CSP Only & $7.74 \pm 4.26$ & Yes & No & - \\
\hline Both PTSD and CSP & $9.68 \pm 4.32$ & Yes & No & No \\
\hline \multicolumn{5}{|l|}{ Social Support } \\
\hline Neither PTSD nor CSP & $2.91 \pm 0.62$ & - & - & - \\
\hline PTSD Only & $2.81 \pm 0.73$ & No & - & - \\
\hline CSP Only & $2.68 \pm 0.65$ & No & No & - \\
\hline Both PTSD and CSP & $2.57 \pm 0.64$ & Yes & No & No \\
\hline \multicolumn{5}{|l|}{ Addiction Severity Index } \\
\hline Neither PTSD nor CSP & $0.09 \pm 0.08$ & - & - & - \\
\hline PTSD Only & $0.12 \pm 0.12$ & No & - & - \\
\hline CSP Only & $0.12 \pm 0.10$ & No & No & - \\
\hline Both PTSD and CSP & $0.17 \pm 0.15$ & Yes & No & No \\
\hline \multicolumn{5}{|l|}{ Mental Health Confidence } \\
\hline Neither PTSD nor CSP & $3.11 \pm 0.57$ & - & - & - \\
\hline PTSD Only & $2.89 \pm 0.69$ & No & - & - \\
\hline CSP Only & $2.91 \pm 0.62$ & No & No & - \\
\hline Both PTSD and CSP & $2.55 \pm 0.65$ & Yes & Yes & Yes \\
\hline
\end{tabular}

ciated with comorbid PTSD and chronic pain limit cognitive and coping abilities [51-52]. When the many physical, emotional, and psychosocial difficulties encountered with both disorders are considered, that per- sons in the current sample demonstrated decreased confidence in coping abilities is logical.

When comparing persons with both disorders with those who had either PTSD or chronic severe pain alone, we found that those with both disorders reported higher 
ratings of psychiatric distress and lower ratings of mental health confidence. Psychiatric or emotional distress, in the forms of depression, anxiety sensitivity, fear, and avoidance, has been identified as one of the features that is responsible for the co-occurrence of PTSD and chronic pain [1,3,9,53-54]. Improving patients' skills and confidence in coping with psychiatric distress would therefore be an important area of clinical intervention for psychiatric outpatients with both PTSD and chronic severe pain. Persons with both disorders were more likely to report a chronic medical condition and lower ratings of PA than persons with PTSD only; for these two characteristics in particular, chronic severe pain appeared to contribute to the differences between persons with both disorders versus those with PTSD only. When comparing persons with either PTSD or chronic severe pain alone with those with neither disorder, we found that persons with a single disorder were more likely to have a chronic medical condition, higher ratings of psychiatric distress, and more stressful life events. As just stated, similar associations have been documented previously.

Our findings indicated that psychiatric outpatients with either both disorders or a single disorder reported a greater number of stressful life events than those with neither disorder. Prior studies have demonstrated that persons with SMI (i.e., psychiatric patients) were more likely to experience ongoing trauma and victimization $[22,25]$. When psychiatric outpatients experience chronic severe pain and also have PTSD, as in the current sample, they may be at greater risk for ongoing stressful or traumatic life events. The current study and previous findings highlight the importance of ascertaining the extent of early trauma and recent or ongoing victimization among psychiatric patients [22] so that clinicians can prioritize appropriate clinical interventions and environmental safety (i.e., change dangerous situations, reduce selfdestructive behaviors) [55].

Of particular note, analysis of medical records indicated that only 7 percent of participants were diagnosed with PTSD by a physician. This finding supports prior research indicating that PTSD is underdiagnosed among psychiatric patients in mental health treatment settings [23-24,40,56]. PTSD may be underdiagnosed because of inadequate assessment of trauma [21,38] or because patients underreport traumatic experiences [39]. Treatment providers may also have difficulty distinguishing complex PTSD symptomatology from other comorbid psychiatric diagnoses. Nevertheless, to provide appropriate interventions, treatment providers must routinely assess for PTSD in psychiatric patients. At a minimum, mental health treatment providers should be aware of the likelihood of a comorbid diagnosis of PTSD when treating psychiatric patients. Our findings also suggest that chronic severe pain and related factors may complicate and exacerbate the patient's experience. The multidisciplinary and biopsychosocial approaches to the management of chronic pain appear relevant to the complex treatment needs of psychiatric outpatients who face numerous physical, emotional, and social challenges [57].

The current study was limited by the single study location, relatively small sample size, and the crosssectional method of data collection. The current sample was mostly composed of racial/ethnic minorities (Hispanic or African American); consequently, our findings may be less generalizable to other settings with different racial/ethnic populations. However, we should note that race was not correlated with PTSD or chronic severe pain. The fact that 46 percent of the study sample had PTSD should be interpreted cautiously because we did not use the "gold standard" for PTSD assessment. While the Clinician-Administered PTSD Scale (CAPS) is the standard measure for PTSD in clinical research settings [58], we elected to use the M.I.N.I. module for PTSD because research assistants and not clinicians administered the interviews. Having clinicians administer the CAPS may have yielded a different percentage of subjects with PTSD. Similarly, the fact that 40 percent of the study sample had chronic severe pain should be interpreted with care because we did not obtain a physician's medical diagnosis of chronic pain. Had we done so, our results (which were based on an assessment tool) would have had greater validity.

In summary, the current study found moderate rates of PTSD and chronic severe pain in psychiatric outpatients. The fact that 40 percent of this particular sample met criteria for chronic severe pain is a unique contribution to the empirical literature. The fact that 24 percent of the sample met criteria for both PTSD and chronic severe pain supports the literature on the co-occurrence of these two disorders across different samples. Psychiatric outpatients with either both disorders or PTSD or chronic severe pain alone demonstrated increased physical and psychosocial stressors. Mental health treatment providers are advised to be aware of the potential for the co-occurrence of PTSD and chronic severe pain and of the many related factors in psychiatric outpatients. Assessment of PTSD 
and trauma-related symptoms is encouraged for all patients in psychiatric treatment settings. To gain a better understanding of the specific comorbidity of PTSD and chronic severe pain, we should, in future research, examine and compare other conditions that co-occur with PTSD or chronic pain (e.g., the co-occurrence of PTSD and diabetes, the co-occurrence of chronic severe pain and another psychiatric condition). Comparing comorbid PTSD and chronic severe pain with other comorbid syndromes would more clearly delineate the factors associated with comorbid PTSD and chronic severe pain and add to our knowledge of the course and the effects of treatment on these two disorders over time.

\section{ACKNOWLEDGMENTS}

We are grateful to the consumers and providers of the Soundview Throgs Neck Community Mental Health Center in the Bronx, New York, for their participation in the research. In particular, we thank staff members Heather Neuhs, CSW, Clinical Director; Elise Richman, MD, Medical Director; Richard Camplone, CSW, Clinical Supervisor; Wilson Rodriguez, Registration Coordinator; and Bonni Bell, Administrative Assistant, for their ongoing assistance and support. We also thank Research Assistants Denecia Pearce and Anna Maria Dimitrova for collecting and managing the data.

This material was based on work supported by the National Institutes of Health, National Institute on Drug Abuse (grant R01-DA015912 awarded to the National Development and Research Institutes; Principle Investigator S. Magura) as part of a controlled trial on self-help for persons with a dual diagnosis.

The authors have declared that no competing interests exist.

\section{REFERENCES}

1. Otis JD, Keane TM, Kerns RD. An examination of the relationship between chronic pain and post-traumatic stress disorder. J Rehabil Res Dev. 2003;40(5):397-405. [PMID: 15080224]

2. Asmundson GJ, Wright KD, Stein MB. Pain and PTSD symptoms in female veterans. Eur J Pain. 2004;8(4):34550. [PMID: 15207515$]$

3. Asmundson GJ, Coons MJ, Taylor S, Katz J. PTSD and the experience of pain: Research and clinical implications of shared vulnerability and mutual maintenance models. Can J Psychiatry. 2002;47(10):930-37. [PMID: 12553128]

4. Bonin M, Norton GR, Frombach I, Asmundson GJ. PTSD in different treatment settings: A preliminary investigation of PTSD symptomatology in substance abuse and chronic pain patients. Depress Anxiety. 2000;11(3):131-33.

[PMID: 10875055]

5. Sherman JJ, Turk DC, Okifjui A. Prevalence and impact of posttraumatic stress disorder-like symptoms on patients with fibromyalgia syndrome. Clin J Pain. 2000;16(2):12734. [PMID: 10870725]

6. Kessler RC, Sonnega A, Bromet E, Hughes M, Nelson CB. Posttraumatic stress disorder in the National Comorbidity Survey. Arch Gen Psychiatry. 1995;52(12):1048-60. [PMID: 7492257]

7. McWilliams LA, Cox BJ, Enns MW. Mood and anxiety disorders associated with chronic pain: An examination in a nationally representative sample. Pain. 2003;106(1-2): 127-33. [PMID: 14581119]

8. Shipherd JC, Beck JG, Hamblen JL, Lackner JM, Freeman JB. A preliminary examination of treatment for posttraumatic stress disorder in chronic pain patients: A case study. J Trauma Stress. 2003;16(5):451-57. [PMID: 14584629]

9. Sharp TJ, Harvey AG. Chronic pain and posttraumatic stress disorder: Mutual maintenance. Clin Psychol Rev. 2001; 21(6):857-77. [PMID: 11497210]

10. Beckham JC, Crawford AL, Feldman ME, Kirby AC, Hertzberg MA, Davidson JR, Moore SD. Chronic posttraumatic stress disorder and chronic pain in Vietnam combat veterans. J Psychosom Res. 1997;43(4):379-89.

[PMID: 9330237]

11. Sharp TJ. The prevalence of post-traumatic stress disorder in chronic pain patients. Curr Pain Headache Rep. 2004; 8(2):111-15. [PMID: 14980145]

12. Verhaak PF, Kerssens JJ, Dekker J, Sorbi MJ, Bensing JM. Prevalence of chronic benign pain disorder among adults: A review of the literature. Pain. 1998;77(3):231-39.

[PMID: 9808348]

13. Guerje O, Simon GE, Von Korff M. A cross-national study of the course of persistent pain in primary care. Pain. 2001; 92(1-2):195-200. [PMID: 11323140]

14. Mersky H, Bogduk N. Classification of chronic pain. In: Mersky H, Bogduk N, editors. IASP task force on taxonomy. 2nd ed. Seattle (WA): IASP Press; 1994. p. 209-14.

15. McFarlane AC, Atchison M, Rafalowicz E, Papay P. Physical symptoms in post-traumatic stress disorder. J Psychosom Res. 1994;38(7):715-26. [PMID: 7877126]

16. Benedikt RA, Kolb LC. Preliminary findings on chronic pain and posttraumatic stress disorder. Am J Psychiatry. 1986;143(7):908-10. [PMID: 3717433] 
17. Asmundson GJ, Norton GR, Allerdings MD, Norton PJ, Larsen DK. Posttraumatic stress disorder and work-related injury. J Anxiety Disord. 1998;12(1):57-69. [PMID: 9549609]

18. Roy-Byrne P, Smith WR, Goldberg J, Afari N, Buchwald D. Post-traumatic stress disorder among patients with chronic pain and chronic fatigue. Psychol Med. 2004;34(2): 363-68. [PMID: 14982142]

19. Hickling EJ, Blanchard EB. Post-traumatic stress disorder and motor vehicle accidents. J Anxiety Disord. 1992;6(3): 285-91.

20. Blanchard EB, Hickling EJ, Taylor AE, Loos WR. Psychiatric morbidity associated with motor vehicle accidents. J Nerv Ment Dis. 1995;183(8):495-504. [PMID: 7643060]

21. Taylor S, Koch WJ. Anxiety disorders due to motor vehicle accidents: Nature and treatment. Clin Psychol Rev. 1995; 15(8):721-38.

22. Goodman LA, Salyers MP, Mueser KT, Rosenberg SD, Swartz M, Essock SM, Osher FC, Butterfield MI, Swanson J; 5 Site Health and Risk Study Research Committee. Recent victimization in women and men with severe mental illness: Prevalence and correlates. J Trauma Stress. 2001;14(4):61532. [PMID: 11776413]

23. Mueser KT, Goodman LB, Trumbetta SL, Rosenberg SD, Osher C, Vidaver R, Auciello P, Foy DW. Trauma and posttraumatic stress disorder in severe mental illness. J Consult Clin Psychol. 1998;66(3):493-99. [PMID: 9642887]

24. Craine LS, Henson CE, Colliver JA, MacLean DG. Prevalence of a history of sexual abuse among female psychiatric patients in a state hospital system. Hosp Community Psychiatry. 1988;39(3):300-304. [PMID: 3356438]

25. Cascardi M, Mueser KT, DeGiralomo J, Murrin M. Physical aggression against psychiatric inpatients by family members and partners. Psychiatr Serv. 1996;47(5):531-33. [PMID: 8740498]

26. Gearon JS, Kaltman SI, Brown C, Bellack AS. Traumatic life events and PTSD among women with substance use disorders and schizophrenia. Psychiatr Serv. 2003;54(4): 523-28. [PMID: 12663840]

27. Mueser KT, Salyers MP, Rosenberg SD, Goodman LG, Essock SM, Osher FC, Swartz MS, Butterfield MI; 5 Site Health and Risk Study Research Committee. Interpersonal trauma and posttraumatic stress disorder in patients with severe mental illness: Demographic, clinical, and health correlates. Schizophr Bull. 2004;30(1):45-57.

[PMID: 15176761]

28. Mueser KT, Rosenberg SD, Goodman LA, Trumbetta SL. Trauma, PTSD, and the course of schizophrenia: An interactive model. Schizophr Res. 2002;53(1-2):123-43. [PMID: 11728845]

29. Sheehan DV, Lecrubier Y, Sheehan KH, Amorim P, Janavs J, Weiller E, Hergueta T, Baker R, Dunbar GC. The MiniInternational Neuropsychiatric Interview (M.I.N.I.): The development and validation of a structured diagnostic psychiatric interview for DSM-IV and ICD-10. J Clin Psychiatry. 1998;59 Suppl 20:22-33; quiz 34-57.

[PMID: 9881538]

30. Cleeland CS, Ryan KM. Pain assessment: Global use of the Brief Pain Inventory. Ann Acad Med Singapore. 1994:23(2): 129-38. [PMID: 8080219]

31. Serlin RC, Mendoza TR, Nakamura Y, Edwards KR, Cleeland CS. When is cancer pain mild, moderate or severe? Grading pain severity by its interference with function. Pain. 1995:61(2):277-84. [PMID: 7659438]

32. Rosenblum A, Joseph H, Fong C, Kipnis S, Cleland C, Portenoy RK. Prevalence and characteristics of chronic pain among chemically dependent patients in methadone maintenance and residential treatment facilities. JAMA. 2003; 289(18):2370-78. [PMID: 12746360]

33. Rosen CS, Drescher KD, Moos RH, Finney JW, Murphy RT, Gusman F. Six- and ten-item indexes of psychological distress based on the Symptom Checklist-90. Assessment. 2000;7(2):103-11. [PMID: 10868247]

34. Watson D, Clark LA, Tellegen A. Development and validation of brief measures of positive and negative affect: The PANAS scales. J Pers Soc Psychol. 1988;54(6):1063-70. [PMID: 3397865]

35. Holmes TH, Rahe RH. The Social Readjustment Rating Scale. J Psychosom Res. 1967;11(2):213-18. [PMID: 6059863]

36. McLellan AT, Parikh G, Bragg A, Cacciola J, Fureman B, Incmikoski R. Addiction severity index, administration manual. 5th ed. Philadelphia (PA): Pennsylvania Department of Veterans Affairs Center for Studies of Addiction; 1990.

37. Appleby L, Dyson V, Altman E, Luchins DJ. Assessing substance use in multiproblem patients: Reliability and validity of the Addiction Severity Index in a mental hospital population. J Nerv Ment Dis. 1997;185(3):159-65. [PMID: 9091597]

38. Carpinello SE, Knight EL, Markowitz FE, Pease EA. The development of the Mental Health Confidence Scale: A measure of self-efficacy in individuals diagnosed with mental disorders. Psychiatr Rehabil J. 2000;23(3):236-43.

39. Shaffer JP. Multiple hypothesis testing. Ann Rev Psychol. 1995;46:561-84.

40. Cohen B. Explaining psychological statistics. 2nd ed. New York (NY): John Wiley \& Sons, Inc; 2000.

41. Sansone RA, Pole M, Dakroub H, Butler M. Childhood trauma, borderline personality symptomatology, and psychophysiological and pain disorders in adulthood. Psychosomatics. 2006;47(2):158-62. [PMID: 16508029]

42. Spiro A 3rd, Hankin CS, Mansell D, Kazis LE. Posttraumatic stress disorder and health status: The veterans health study. J Ambul Care Manage. 2006;29(1):71-86. [PMID: 16340621] 
43. Parker RS, Rosenblum A. IQ loss and emotional dysfunctions after mild head injury incurred in a motor vehicle accident. J Clin Psychol. 1996;52(1):32-43.

[PMID: 8682910]

44. Kerns RD, Otis J, Rosenberg R, Reid MC. Veterans' reports of pain and associations with ratings of health, health-risk behaviors, affective distress, and use of the healthcare system. J Rehabil Res Dev. 2003;40(5):371-79. [PMID: 15080222]

45. Back SE, Brady KT, Jaanimagi U, Jackson JL. Cocaine dependency and PTSD: A pilot study of symptom interplay and treatment preferences. Addictive Behav. 2006;31(2): 351-54. [PMID: 15951125]

46. Manchikanti L, Cash KA, Damron KS, Manchukonda R, Pampati V, McManus CD. Controlled substance abuse and illicit drug use in chronic pain patients: An evaluation of multiple variables. Pain Physician. 2006;9(3):215-25. [PMID: 16886030$]$

47. Lampe A, Doering S, Rumpold G, Solder E, Krismer M, Kanter-Rumplmair W, Schubert C, Sollner W. Chronic pain syndromes and their relation to childhood abuse and stressful life events. J Psychosom Res. 2003;54(4):361-67. [PMID: 12670615]

48. Marmar CR, McCaslin SE, Metzler TJ, Best S, Weiss DS, Fagan J, Liberman A, Pole N, Otte C, Yehuda R, Mohr D, Neylan T. Predictors of posttraumatic stress in police and other first responders. Ann N Y Acad Sci. 2006;1071:1-18. [PMID: 16891557]

49. Evers AW, Kraaimaat FW, Geenan R, Jacobs JW, Bijlsma JW. Pain coping and social support as predictors of longterm functional disability and pain in early rheumatoid arthritis. Behav Res Ther. 2003;41(11):1295-1310. [PMID: 14527529]
50. Zautra AJ, Johnson LM, Davis MC. Positive affect as a source of resilience for women in chronic pain. J Consult Clin Psychol. 2005;73(2):212-20. [PMID: 15796628]

51. Beck JG, Freeman JB, Shipherd JC, Hamblen JL, Lackner JM. Specificity of Stroop interference in patients with pain and PTSD. J Abnorm Psychol. 2001;110(4):536-43.

[PMID: 11727943]

52. Beck JG, Gudmundsdottir B, Shipherd JC. PTSD and emotional distress symptoms measured after a motor vehicle accident: Relationship with pain coping profiles. J Psychopathol Behav Assess. 2003;54(4):219-27. [PMID: 16518453]

53. Norton PJ, Asmundson GJ. Amending the fear-avoidance model of chronic pain: What is the role of physiological arousal? Behav Ther. 2003;34(1):17-30.

54. Keane TM, Barlow DH. Posttraumatic stress disorder. In: Barlow DH, editor. Anxiety and its disorders: The nature and treatment of anxiety and panic. New York (NY): Guildford Press; 2002. p. 418-53.

55. Najavits LM. Seeking safety: A treatment manual for PTSD and substance abuse. New York (NY): Guildford; 2001.

56. Brady KT, Killeen TK, Brewerton T, Lucerini S. Comorbidity of psychiatric disorders and posttraumatic stress disorder. J Clin Psychiatry. 2000;61 Suppl 7:22-32. [PMID: 10795606]

57. Stanos S, Houle TT. Multidisciplinary and interdisciplinary management of chronic pain. Phys Med Rehabil Clin N Am. 2006;17(2):435-50,vii. [PMID: 16616276]

58. Weathers FW, Keane TM, Davidson JR. Clinicianadministered PTSD scale: A review of the first ten years of research. Depress Anxiety. 2001;13(3):132-56.

Submitted for publication May 30, 2006. Accepted in revised form January 30, 2007. 